\title{
Multiscale Pore Structure Analysis of Nano Titanium Dioxide Cement Mortar Composite
}

\author{
Davood Shafaei ${ }^{1}$, Shangtong Yang ${ }^{1 *}$, Leonard Berlouis ${ }^{2}$, James Minto ${ }^{1}$ \\ ${ }^{1}$ Department of Civil and Environmental Engineering, University of Strathclyde, Glasgow, G1 1XJ, United Kingdom \\ ${ }^{2}$ Department of Pure and Applied Chemistry, University of Strathclyde, Glasgow, G1 1XL, United Kingdom
}

\section{ABSTRACT}

The effects of nano- $\mathrm{TiO}_{2}(\mathrm{NT})$ on the multiscale pore system and morphology of cement mortars were studied by X-ray computed tomography (X-CT), scanning electron microscopy (SEM), and BrunauerEmmett-Teller (BET) method. The obtained results from X-CT showed that microscale pores (from $20 \mu \mathrm{m}$ to $200 \mu \mathrm{m}$ ) of mortars mixed with $2.5 \mathrm{wt} \% \mathrm{NT}$ were significantly refined. When the content of NT is more than $2.5 \mathrm{wt} \%$, the total pore volume and the number of pores begin to increase. However, when the amount of NT exceeds the optimal value, e.g., $(2.5<\mathrm{NT}<5 \%)$, the recorded 2D porosity (void area fraction), are still lower than the reference sample. Meanwhile, the microscopy results proved that, by adding $2.5 \mathrm{wt} \% \mathrm{NT}$, the pores of cement mortars were best filled, resulting in a more homogenous morphology. At the nanoscale, the BET results revealed a clear trend of increasing surface area and pore volume of the NT cement mortars, over the entire range of NT percentages, i.e., from $0 \mathrm{wt} \%$ to $10 \mathrm{wt} \%$. This could stem from the formation of nanosized needle-shaped products in the presence of the nanoparticles. Further, the permeability of NT cement mortars was measured using a high-pressure core holder and the results showed that $2.5 \mathrm{wt} \%$ NT inclusions could reduce the permeability of the cement mortars by $32 \%$. However, adding more NT $(>2.5 \mathrm{wt} \%)$ led to higher permeability. This is in line with the microscale pore analysis from X-CT. It can be concluded that adding a certain amount of NT (around $2.5 \mathrm{wt} \%$ ) can modify the pore structure of cement mortars by changing the harmful microscale pores (permeability related) to the nano-sized benign pores, leading to a much stronger durability of cement-based materials.

\section{KEYWORDS}

Nano titanium dioxide (NT); X-ray computed tomography (X-CT); Brunauer-Emmett-Teller (BET); Permeability; Scanning electron microscopy (SEM).

* Corresponding author. Tel: +44 141548 3273. Email: shangtong.yang@ strath.ac.uk. 


\section{INTRODUCTION}

Nano titanium dioxide (NT) has attracted increasing attention for application in cementitious materials to provide unique properties to architectural buildings and structures. Under ultraviolet light and humidity, titanium dioxide $\left(\mathrm{TiO}_{2}\right)$ can decompose a wide range of organic and inorganic air pollutants, providing cleaner air and better health for humans and other living creatures. The process of photodecomposition through light absorption is known as photocatalysis and titanium dioxide is considered one of the most powerful photocatalysts available. When mixing with cement, the "selfcleaning" property of $\mathrm{TiO}_{2}$ can be utilised on a large-scale, e.g., to help urban cities improve their air quality. Moreover, the white colour of titanium dioxide cement/concrete is generally appealing in terms of architectural needs.

In the last decade, titanium dioxide cement has been applied in a number of laboratories and real civil engineering projects, e.g., the Jubilee Church in Rome. The decomposition of the pollutants lead to the formation of water, $\mathrm{CO}_{2}$ and other harmless compounds which can be naturally washed away by rain water and so it is a completely green and environmental-friendly procedure. The photocatalytic and self-cleaning properties of $\mathrm{TiO}_{2}$ in cementitious materials have been extensively discussed [1-3]. Chen and Poon [4] investigated the removal of nitrogen oxides on $\mathrm{TiO}_{2}$-cement composites with 2 different $\mathrm{TiO}_{2}$ percentages and different curing methods.

Demeestere et al. [5] evaluated the potential of heterogeneous photocatalytic removal of toluene from outdoor air using ceramic building materials incorporating $\mathrm{TiO}_{2}$ under different ambient conditions. Though there are still a number of outstanding issues that need to be addressed in order to increase the efficiency of air pollutants removal by $\mathrm{TiO}_{2}$ enriched building materials, it did demonstrate a very promising potential as a future smart city feature. Apart from the photocatalytic properties, the mechanical properties, microstructures and hydration of the $\mathrm{TiO}_{2}$ cement composites have also been studied. Zhang et al. [6] studied the influence of NT on pore structure and chloride permeability of pavement concrete. Lackhoff et al. [7] showed an increase in the compressive strength of mortars 
containing NT particles. The influence of NT particles on the hydration of cementitious materials was examined by researchers [8-10] and shown to enhance hydration due to the high specific surface area of NT particles, through an increase in the nucleation sites for that reaction. Furthermore, the addition of NT particles has been shown to improve the densification of the microstructure, thereby enhancing the durability of the cementitious materials $[11,12]$.

Compared with the photocatalytic and mechanical properties of the NT-cement mortar, the durability of this composite material though is much less known. This casts doubts or uncertainty in the widespread application of the NT-cement mortar composite for construction. The permeability of concrete is of significant concern and this is of particular concern in harsh and aggressive environments. Most durability problems, such as the corrosion of steel reinforcement, damage by freeze-thaw cycles, attack by sulphates and acids, and alkali aggregate reaction, are controlled or affected by the pore system of the concrete. In fact, due to the nano particle size and hydrophilic property, NT can change the pore system of cement paste across different length scales. Therefore, there is a well justified need to investigate the multiscale pore structures and permeability of NTcement mortar composite materials.

This paper attempts to determine the pore system of NT- cement mortars across length scales with different NT dosages. X-ray computed tomography (X-CT) is used to analyse the mesoscale pore structures of NT mortars with NT percentages of $0 \mathrm{wt} \%, 2.5 \mathrm{wt} \%, 3.5 \mathrm{wt} \%, 5 \mathrm{wt} \%$ and $10 \mathrm{wt} \%$. 3D pore structures of the NT mortars are obtained and evaluated. In addition, the scanning electron microscopy (SEM) is used to compare the morphologies of the samples with different NT inclusions. Meanwhile, elementary analysis is performed using an energy-dispersive X-ray spectroscopy $\left(\mathrm{EDAX}^{\circledR}\right)$. Moreover, the nanoscale surface areas and the nano pore volume and shapes of the NT mortar samples are obtained by Brunauer-Emmett-Teller (BET) and Barrett-Joyner-Halenda (BJH) analysis. Furthermore, the permeability is measured using a high-pressure core holder with a sensitive and automated measurement capability. 


\section{EXPERIMENTAL PROGRAM}

\subsection{Materials}

Different percentages of OPC (Provided by Jewson, which complies with BS EN197 Part 1:2000 [13], with a Grade of $\left.42.5 \mathrm{~N} / \mathrm{mm}^{2}\right)$, was replaced with anatase different amounts of NT, viz., (0 wt $\%$, $2.5 \mathrm{wt} \%, 3.5 \mathrm{wt} \%, 5 \mathrm{wt} \%$ and $10 \mathrm{wt} \%)$. Other researchers have also used large NT dosage in their studies $[14,15]$. Lower dosage of NT in the cementitious materials may be insufficient to ensure selfcleaning and air purification over longer periods [15]. Therefore, higher percentages of NT were chosen in this study. Natural river sand, with a minimum particle size of $200 \mu \mathrm{m}$ served as the fine aggregate. The mineralogical phases and chemical composition of the raw materials used were obtained from the X-ray diffraction (XRD) and X-ray fluorescence (XRF) analyses. The NT particles used in this research was obtained from ALDRICH and had a specific surface area of $35-65 \mathrm{~m}^{2} / \mathrm{g}$. A summary of the physical properties of the NT, sand and cement is given in Table 1 and Table 2 . Deionised water, with a pH value of 7.5 at $22^{\circ} \mathrm{C}$, was used throughout the experimental research.

Table 1: Properties of Nano Titanium Dioxide $\mathrm{TiO}_{2}$

\begin{tabular}{|c|c|}
\hline Properties & Nano Titanium Dioxide \\
\hline Particulates & Anatase based \\
\hline $\mathrm{PH}$ & $3.5-4.5$ \\
\hline Particle size $(\mathrm{nm})^{1}$ & 21 \\
\hline Moisture content ${ }^{1}$ & 0.42 \\
\hline Melting point ${ }^{1}$ & $1850^{\circ},>350^{\circ} \mathrm{C}$ (lit.) \\
\hline Poisson's ratio & 0.27 \\
\hline Density $\left(\mathrm{Kg} / \mathrm{m}^{3}\right)^{1}$ & 3.97 \\
\hline Surface area $\left(\mathrm{m}^{2} / \mathrm{g}\right)^{1}$ & $35-65(\mathrm{BET})$ \\
\hline Molar mass (g/mol) & 79.8 \\
\hline
\end{tabular}

1). Referential values taken from (ALDRICH)

Table 2: Physical properties of the materials used

\begin{tabular}{lcc}
\hline Properties & Fluvial sand & CEM I $42.5 \mathrm{~N}$ \\
\hline Size & $200 \mu \mathrm{m}-4 \mathrm{~mm}$ & $0.2 \mu \mathrm{m}-200 \mu \mathrm{m}$ \\
Specific density $\left(\mathrm{g} / \mathrm{cm}^{3}\right)^{2}$ & 2.56 & 3.112 \\
$\mathrm{D}_{\min }(\mathrm{mm}, \mu \mathrm{m})$ & $200 \mu \mathrm{m}$ & $0.23 \mu \mathrm{m}$ \\
$\mathrm{D}_{\max }(\mathrm{mm}, \mu \mathrm{m})$ & $4.3 \mathrm{~mm}$ & $160 \mu \mathrm{m}$ \\
Shape factor $(\xi)^{1}(-)$ & 1.10 & 1.73 \\
Specific surface area $\left(\mathrm{m}^{2} / \mathrm{m}^{3}\right)$ & $17,568(\mathrm{BET})$ & $992,145(\mathrm{BET})$ \\
\hline
\end{tabular}

1). Referential values taken from (ALDRICH).

2). Provided by Jewson (Scotland). 


\subsection{Mixing Procedure}

The experimental study involved the application of a pan mixer with $50 \mathrm{~kg}$ capacity. The fine aggregate was first poured into the pan-mixer, followed by the OPC CEM I $42.5 \mathrm{~N}$, under dry conditions. They were mixed for 45 seconds to ensure homogeneity. The mixing continued for another 2.5 minutes before water, already mixed with nano titanium dioxide was added and the mixing was allowed to continue for another 7 minutes.

As NT particles tend to agglomerate when mixing with water and conventional agitators cannot break down these hard agglomerates, a Silverson high shear mixer was employed in order to deagglomerate these particles and returning them to the desired particle size. Uniformly distributed nanoparticles play the adhesive role that firmly bonds hydration products and transition zones together and set up a new network in which the nanoparticles are nodes, based on the original network structure of hardened mortars, bonding more nanoscale C-S-H gel and forming a three-dimensional network structure.

The recorded mix design code for each sample is presented in Table 3. Slump tests were then carried out according to BS EN 12350-2:2009 [16]. The mix proportion design resulted in a slump ranging from 12 to $24 \mathrm{~mm}$ and vebe time ranging from 9 and 16 seconds which met the required workability based on BS EN 12350-2:2009. The mix had a constant water/equivalent cement ratio of 0.55. A constant quantity of sand $\left(681 \mathrm{~kg} / \mathrm{m}^{3}\right)$ and water $\left(125 \mathrm{~kg} / \mathrm{m}^{3}\right)$ were used in this research.

Table 3: Mix proportions of test specimens

\begin{tabular}{ccc}
\hline Code number & $\begin{array}{c}\text { Cement } \\
\left(\mathrm{kg} / \mathrm{m}^{3}\right)\end{array}$ & $\begin{array}{c}\text { Cement replacement } \\
(\mathrm{wt} \%)\end{array}$ \\
\hline $\mathrm{ACM}$ N & $\mathrm{TiO}_{2}$ \\
$\mathrm{AM} 2.5$ & 227.3 & 0 \\
$\mathrm{AM} 3.5$ & 221.6 & 2.5 \\
$\mathrm{AM} 5$ & 219.3 & 3.5 \\
AM10 & 204.5 & 5 \\
\hline
\end{tabular}




\subsection{Specimen Preparation}

\subsubsection{Specimen preparation for $X$-ray $C T$ scans and BET analysis}

After ascertaining that the mixture met the required workability and cohesion for the specified design mix, moulds for cement mortars specimens with diameters of $25 \mathrm{~mm}$ and length of $75 \mathrm{~mm}$ were designed. The moulds then treated with oil to enable later separation from the mortars, which was poured into the mould to create the design suitable for X-ray computed tomography system. Following removal from the moulds, they were stored in a water bath at $20 \pm 3{ }^{\circ} \mathrm{C}$ and $65 \%$ relative humidity until the required curing age of 28 days before testing which complies with ASTM C5112019 Standards [17].

In the present research, in order to perform the BET analysis, the samples were dried in the oven at $65^{\circ} \mathrm{C}$ for 24 hours and then ground to fine powder and passed through a $200 \mu \mathrm{m}$. For microscopy test, circular samples with a diameter of $12 \mathrm{~mm}$ and thickness $3 \mathrm{~mm}$ were made using a diamond precision cutter and cured for 28 days. The circular samples were dried in a vacuum oven at $45^{\circ} \mathrm{C}$ until a constant weight was reached. These specimens were then impregnated with epoxy, polished and sputter coated.

For permeability test, cement mortars cylinders, with the diameter of $100 \mathrm{~mm}$ and the length of 150 $\mathrm{mm}$ were cast and vibrated in a table vibrator. The specimens were then demoulded and left to cure for 28 days. Circular sections with the diameter of $35 \mathrm{~mm}$ and thickness $70 \mathrm{~mm}$ were extracted from the samples using a diamond precision cutter. Each sample was prepared by a process of vacuum saturation in which the specimen was placed under vacuum for 4 hours and then submerged by deaerated water while it was still under vacuum. The vacuum was maintained for an additional 6 hours and then released. The specimen was then left under water for 10 hours prior to insertion into a permeability cell. An essential requirement of permeability testing is that the pore space must be fully saturated by the permeating fluid. In practice, this implies that for a water-based permeability testing, all air within the communicating pores must be removed and replaced with water. 


\subsection{Testing procedure}

\subsection{1. $2 D$ and $3 D$ Porosity analysis}

In order to investigate the nature of the pore structure configuration of the composite mortar matrix, $\mathrm{X}$-CT tests were carried out. The use of cylindrical samples allows minimization of beam hardening artefacts due to the X-ray penetration length being equal from all angles as the cylinder rotates around its axis in the scan. Unlike the more traditional methods for characterization of microstructure, e.g., mercury intrusion porosimetry (MIP) and scanning electron microscope (SEM), X-CT provides a more complete picture of the pore distribution, including interconnected and isolated pores, with 3D images and no need of any prior drying preparation. Drying cementitious samples under high vacuum might produce irreversible changes in the microstructure [18-20].

X-ray tomography can thus be well employed in understanding the meso-structure of building materials [21] and the porosity of concrete [22]. The cement mortar samples were subjected to CT scans with a Nikon XT H 225/320 LC at the Advanced Materials Research Laboratory (AMRL) CT scanner facility at the University of Strathclyde. Scans of $20.0 \mu \mathrm{m}$ resolution were achieved at an operating voltage of $145 \mathrm{kV}$, a current of $100 \mu \mathrm{A}$, and with 3141 projections recorded during one full rotation of the sample. This operating condition resulted in approximately 37 minutes per scan, excluding sample setup and background detector calibration. The $31412 \mathrm{D}$ projections were reconstructed into a 3D volume with CT PRO 3-D (Nikon Metrology).

Quantitative analysis was carried out using the image analysis software ImageJ and the results visualised in 3D with ParaView. Low density air filled voids were distinguished from the higher density cement matrix by their relative difference in X-ray attenuation, then binary segmentation was applied (via a global threshold) so that the volumes of each phase, and hence the porosity, could be calculated.

The procedure for calculating the porosity involves selecting the object using an adaptive square around the object, and then removing all air from the 3D data set in order to calculate the average void fraction using the volume analysis tool. To increase efficiency in data acquisition, two samples 
were analysed at the same time which also helped to have more accurate analysis by selecting the same setting for both samples. The experiment setup for micro-XCT analysis and the final 3D visualization of porosity is presented in Figure 1.

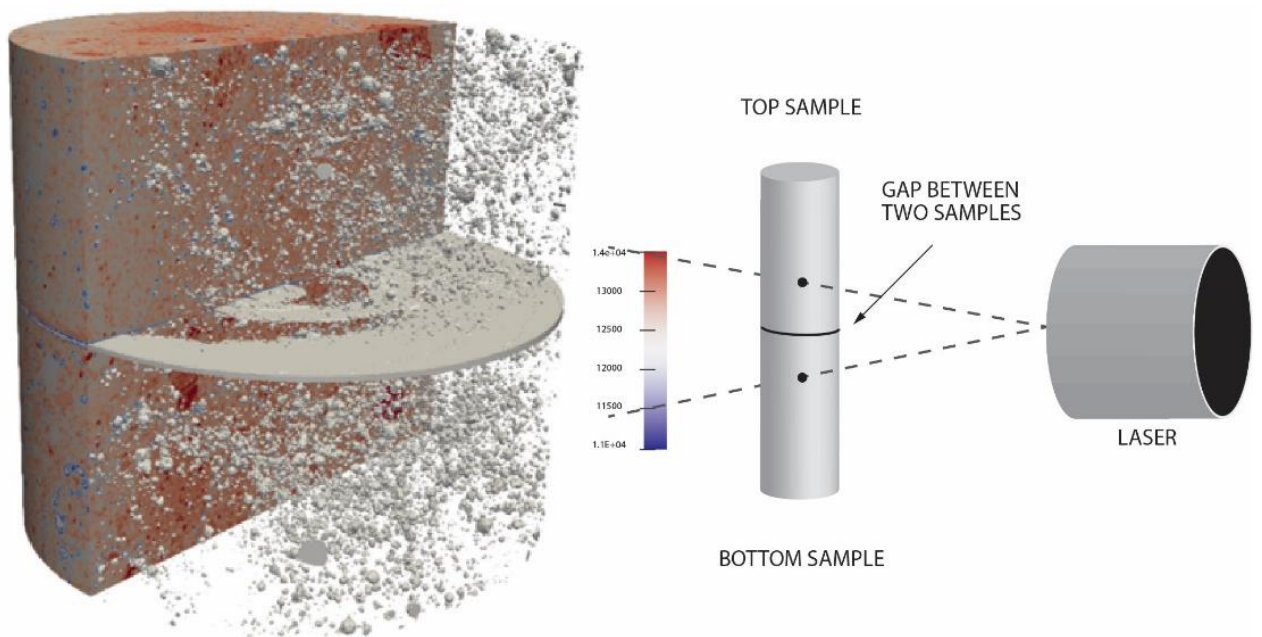

Figure 1: Experiment Setup for micro-XCT analysis and the final 3D visualization of porosity.

\subsubsection{Permeability measurement using high pressure core holder}

A general view of the experimental setup for conducting water-permeability measurement using a high pressure Hassler type core holder is presented in Figure 2. Cement mortars samples containing different dosage of NT, i.e., (0 wt $\%, 2.5 \mathrm{wt} \%, 3.5 \mathrm{wt} \%, 5 \mathrm{wt} \%$ and $10 \mathrm{wt} \%)$ in cylindrical geometry with a diameter of $35 \mathrm{~mm}$ and length of $70 \mathrm{~mm}$ were extracted from the samples using a diamond precision cutter.

In order to improve the analysis of the data, the results of permeability measurement of the cement mortars were compared with the result of a low permeability sandstone core and a steel cylinder with zero permeability, each with the same dimensions as the cement mortars. Permeability measurement was performed under steady-state conditions.

The vacuum saturated core sample was mounted in the core holder and then placed under a suitable confining pressure (3 MPa) to ensure a tight seal around the sample and minimal bypass of injected fluid around the sample. The water was then flowed through the sample under a constant pressure gradient (max $2 \mathrm{MPa}$ ) until steady-state flow was reached. 
The flow rate and the pressure drop were then recorded. The test was repeated at different sets of flow rate and inlet pressure and the data were recorded. Controlling the temperature of the environment surrounding the permeability set-up contributes to pressure stability, so the test temperature was maintained at $22 \pm 1.0^{\circ} \mathrm{C}$. Finally, de-aired water was used for the experiment as well as for applying the confining pressure.

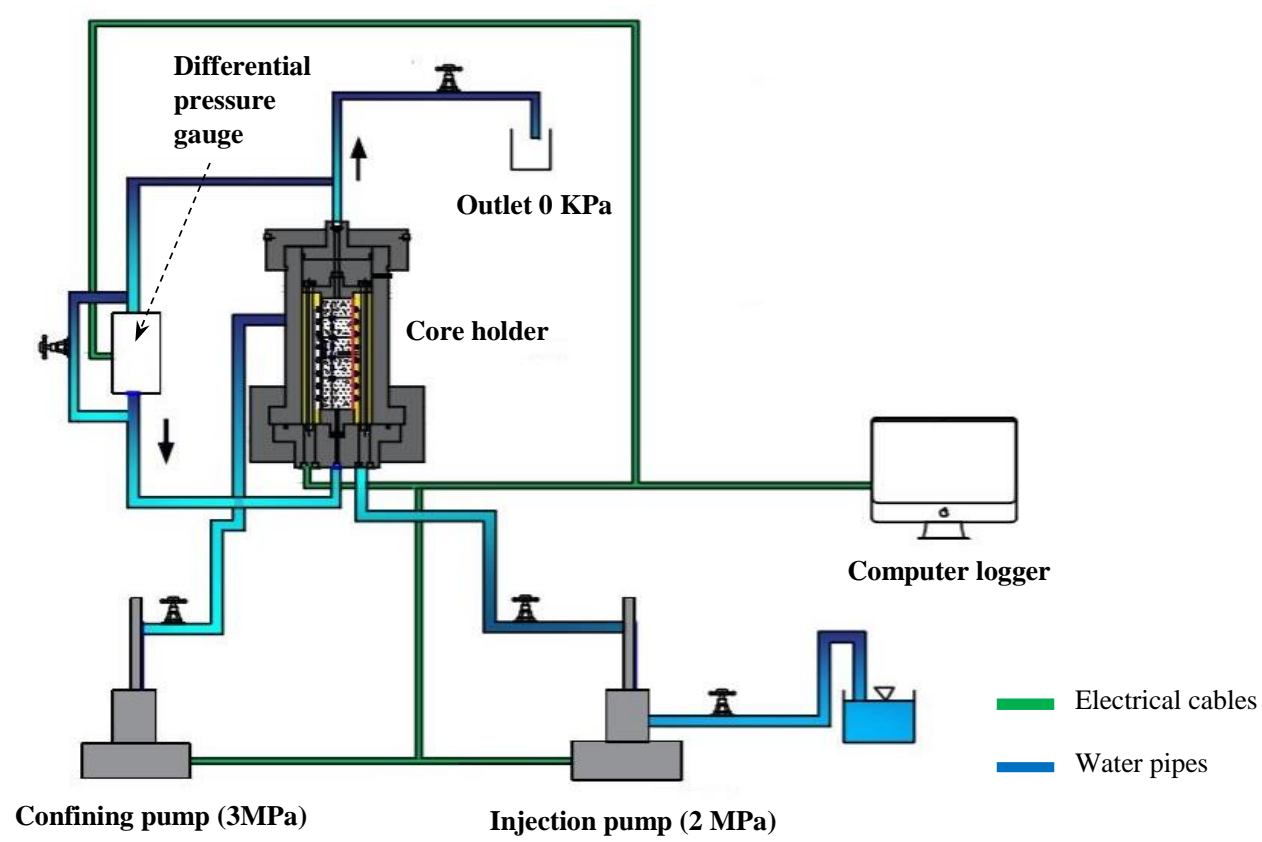

Figure 2: A general view of the experimental setup for conducting the water permeability measurement of the cement mortars using high pressure core holder.

A constant pressure was applied to the inlet of the sample and the pressure drop from inlet to outlet was recorded with a differential pressure transducer. The cumulative volume injected in order to maintain this constant pressure was recorded at ten second intervals, accurate to $\pm 0.5 \mathrm{~mm}^{3}$, and was used to calculate flow rate. Permeability was calculated by rearranging Darcy's law:

$$
Q=-\frac{k A\left(p_{b}-p_{a}\right)}{\mu \mathrm{L}}
$$

where $A$ is the cross-sectional area of the sample $\left(m^{2}\right), Q$ is the flow rate $\left(\frac{m^{3}}{s}\right), k$ is the permeability of the medium $\left(m^{2}\right), \mu$ is dynamic viscosity of the fluid, $\mathrm{L}$ is the sample length and $\left(p_{b}-p_{a}\right)$ is the measured pressure drop. 


\subsubsection{Microstructural analysis using SEM and EDS}

SEM analysis was carried out in the secondary electron mode using the field emission scanning electron microscope (FE-SEM). A HITACHI SU-6600, operated with an acceleration voltage of 20 keV was used. Furthermore, elementary analysis was performed using energy-dispersive X-ray spectroscopy (EDS) with EDS measurements arranged in rectangular grids of $10 \times 20$ points (vertical and horizontal distances of $5 \mathrm{~mm}$ ).

\subsubsection{Measurement of nano surface area, pore size and pore volume using BET}

The specific surface area and pore volume of the composite powders were determined by physical adsorption of a gas on the surface of the solid and by calculating the amount of adsorbate gas corresponding to a monomolecular layer on the surface. Physical adsorption results from relatively weak forces (van der Waals forces) between the adsorbate gas molecules and the adsorbent surface area of the test powder. The determination is usually carried out at the temperature of liquid nitrogen. The amount of gas adsorbed can be measured by a volumetric or continuous flow method. The surface areas and the pore size diameter were calculated by the Brunauer-Emmett-Teller (BET) and BarrettJoyner-Halenda $(\mathrm{BJH})$ procedures, respectively, from data obtained using a micromeritics ASAP2020 surface area and porosimetry system.

\section{RESULTS AND DISCUSSIONS}

\section{1. $2 D$ and $3 D$ Porosity obtained from $X$-ray $C T$}

Figure 3 shows the CT images for the sample AM10 (containing $10 \mathrm{wt} \% \mathrm{NT}$ ), located at the bottom, and the sample AM2.5 (containing $2.5 \mathrm{wt} \% \mathrm{NT}$ ) at the top. These two samples (percentages) demonstrate the highest porosity (AM10) and lowest porosity (AM2.5) amongst all specimens tested. The 3D volumetric void fraction and 2D area void fraction for sample AM10 and AM2.5 are (7.06\%, $7.83 \%)$ and $(2.42 \%, 3.26 \%)$ respectively.

The slightly different volumetric value can be explained by different sub volumes (top and bottom edges are cropped to eliminate edge artefacts) and other possible causes of difference can arise from the material segmentation from the background. 

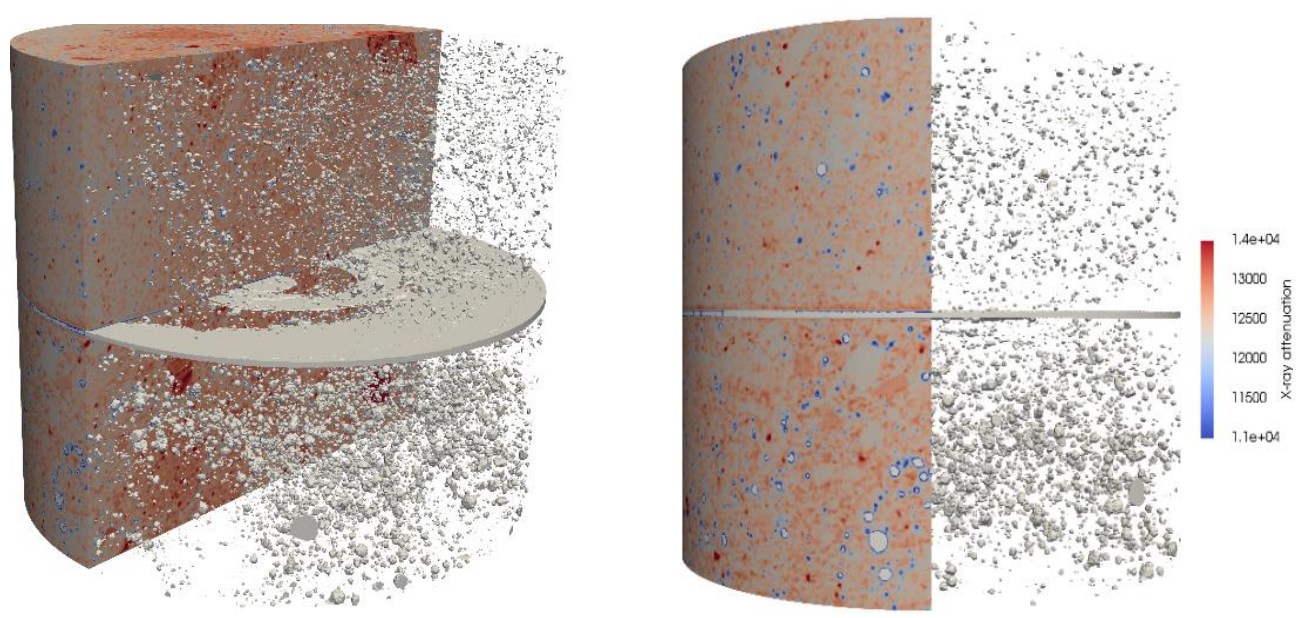

Figure 3: 3D visualization porosity of sample AM10 (bottom) and AM2.5 (top).

The recorded 3D volumetric void fractions and 2D area void fractions for mortars with different doses of NT at 28 days curing are presented in Table 4. A refinement of the structure can also be noticed by comparing 3D visualization of porosity of sample ACM (bottom) and AM2.5 (top) (as illustrated in Figure 4).

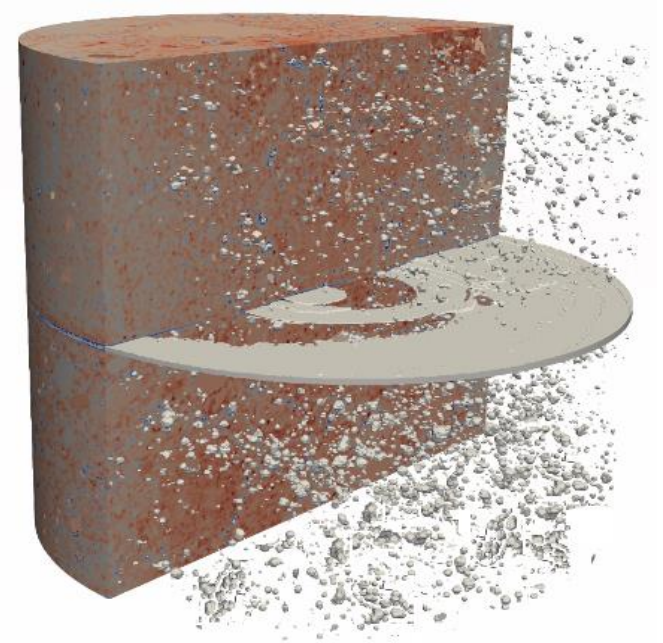

Figure 4: 3D visualization of porosity of sample ACM (bottom) and AM2.5 (top).

Table 4: Void fractions of mortars with different dosages of NT at 28 days curing.

\begin{tabular}{cccc}
\hline $\begin{array}{c}\text { Code number of } \\
\text { Cement Mortars }\end{array}$ & $\begin{array}{c}\text { Cement replacement } \\
(\mathrm{wt} \%)\end{array}$ & $\begin{array}{c}\text { Nano }-\mathrm{TiO}_{2} \\
\text { fractions }(\%)\end{array}$ & $\begin{array}{c}\text { 2D Area void } \\
\text { fractions }(\%)\end{array}$ \\
\hline ACM & 0 & 6.67 & 7.81 \\
$\mathrm{AM} 2.5$ & 2.5 & 2.42 & 3.26 \\
$\mathrm{AM} 3.5$ & 3.5 & 2.98 & 3.66 \\
$\mathrm{AM} 5$ & 5 & 5.87 & 5.95 \\
$\mathrm{AM} 10$ & 10 & 7.06 & 7.83 \\
\hline
\end{tabular}


The improvement of the meso-structure of the cement mortars can be clearly noticed. Figure 5 presents a comparison of the $2 \mathrm{D}$ image for the maximum porosity cross section from the samples AM2.5 and AM10 respectively. These two samples have the least porosity and the largest porosity; to pick up the cross section images which have the largest porosity from both samples (as pointed out in Figure 5b) show very interesting findings.

As shown in Figure 5(c), NT particles tend to agglomerate when the optimal value is exceeded. causing internal defects to form in mortars, which will certainly influence the overall voids and the total porosity. Simultaneously, excess NT (i.e., NT $\geq 5 \mathrm{wt} \%$ ), is difficult to spread evenly and some internal defects would likely form in NT cement mortars (as illustrated in Figure 5c). For AM2.5 as shown in Figure 5(a), the NT is very much more uniformly distributed and the pores (in black) are considerably smaller in size and less in number than those in Figure 5(c).

The difference can be quantitatively calculated from Table 4, i.e., the 3D volumetric void fraction of AM10 is about 3 times that of AM2.5. Moreover, the relationships between 3D volumetric void fractions, 2D Area void fractions and NT content for 28 days curing are presented in Figure 6.
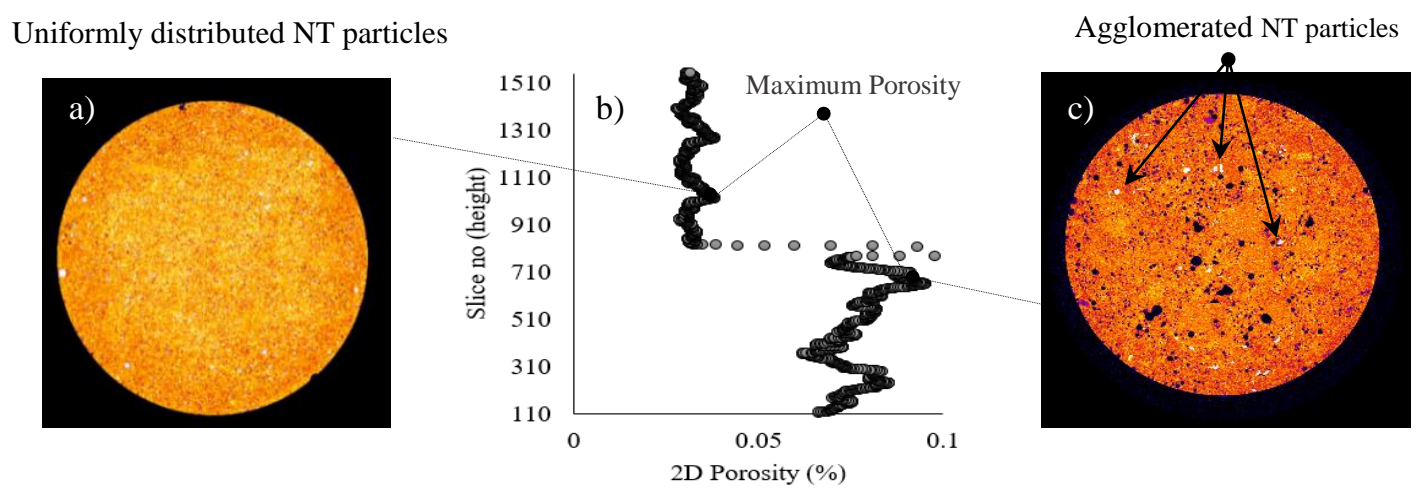

Figure 5: a) 2D analysis of porosity of sample AM2.5 (Slice number 1035), b) 2D porosity (void area \%) from top to bottom of sample AM10 (bottom) and AM2.5 (top), c) 2D analysis of porosity of sample AM10 (slice number 645).

2D analysis of the slices from top to bottom through the sample has been performed in order to calculate the actual porosity variation within the sample. X-CT scanning porosity profiles of samples with highest porosity (AM10 at bottom) and lowest porosity (AM2.5 at top) and their corresponding average $\mathrm{x}$-ray attenuation (density) are presented in Figures 7 and 8. 
The study has shown that the range $2.5 \mathrm{wt} \%$ to $3.5 \mathrm{wt} \%$ of NT is the optimal amount for improving the microstructure of the cement mortar (total average porosity reduced by $60.1 \%$ and $54.2 \%$ respectively). When the content of NT is more than $3.5 \mathrm{wt} \%$, the total pore volume and the number of pores begin to increase.

When the amount of NT exceeds the optimal value (i.e., NT $>2.5 \mathrm{wt} \%$ ), the recorded 3D volumetric void fractions and 2D area void fractions observed for AM5 $(5.87 \%, 5.95 \%)$ are lower than these for the reference sample $\mathrm{ACM}(6.67 \%, 7.81 \%)$. 2D X-CT scanning porosity profiles of AM2.5 at (bottom) and AM3.5 at (top) and their corresponding average x-ray attenuation (density) are presented in Figures 9 and 10.

The recorded 3D volumetric void fractions indicate that sample AM2.5 contains 3,931 pores with a volume fraction of $2.42 \%$ (the lowest volume voids among the samples). Specimens AM5 and AM10 have 6,212 and 6,965 pores with pore volume fractions increasing to $5.87 \%$ and $7.06 \%$, respectively (the largest volume of voids among all samples).

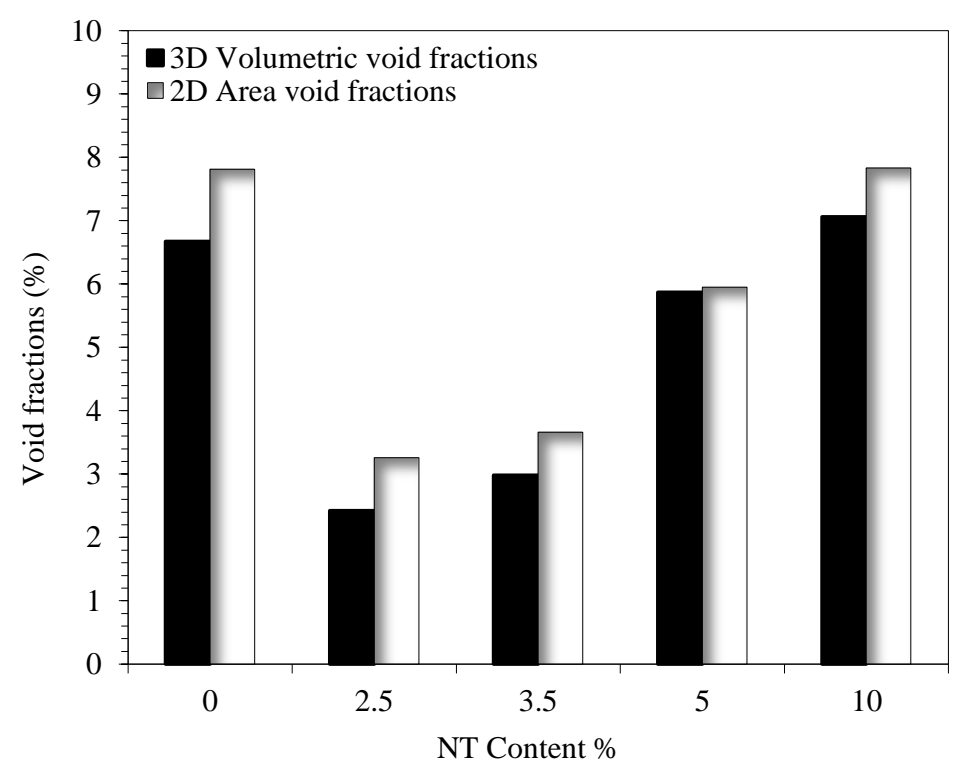

Figure 6: Relationships between 3D volumetric void fractions, 2D Area void fractions and NT content at 28 days. 


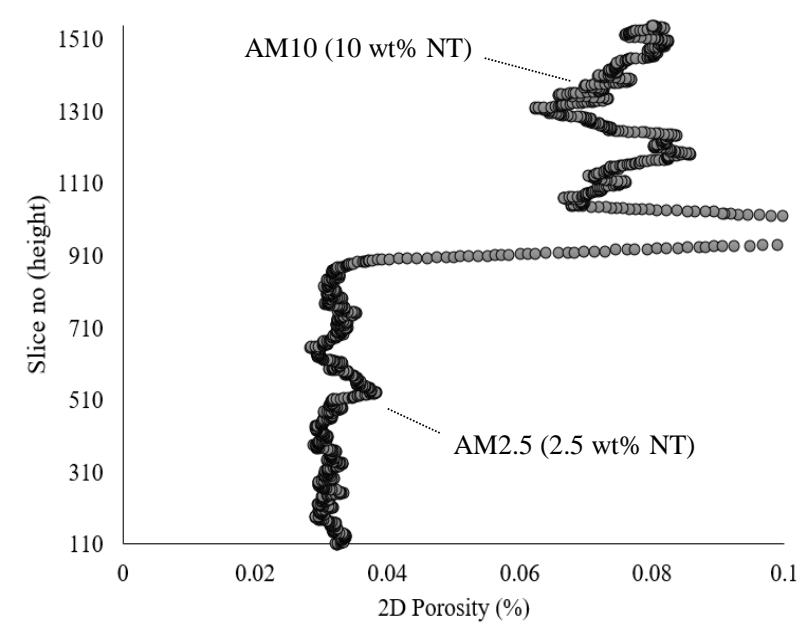

Figure 7: 2D porosity (void area \%) from top to bottom of sample AM2.5 (bottom) and AM10 (top).

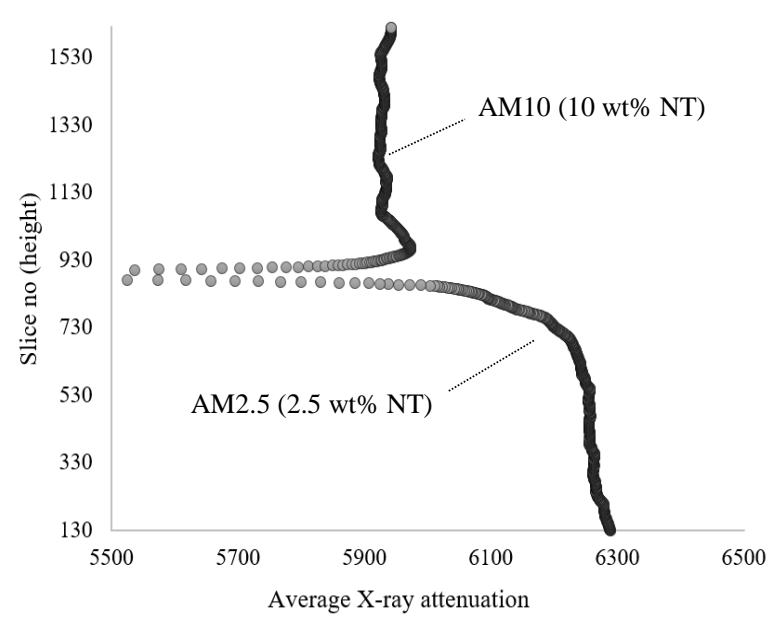

Figure 8: Average x-ray attenuation of sample AM2.5 (bottom) and AM10 (top).

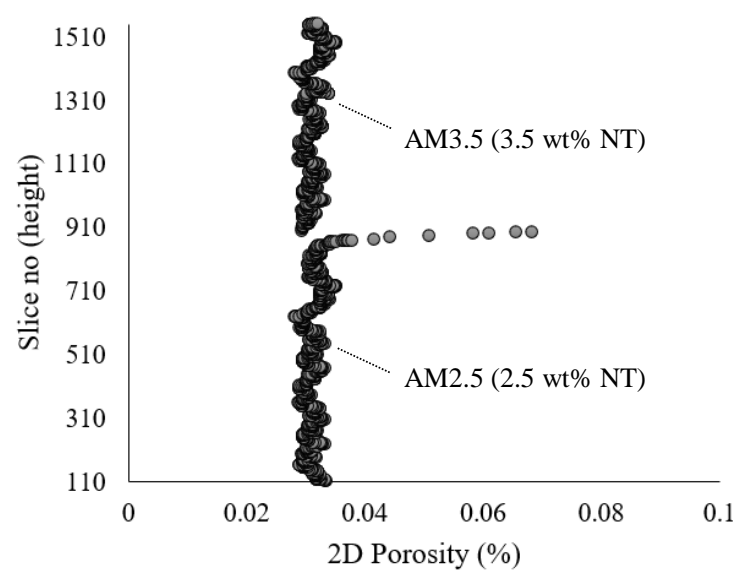

Figure 9: 2D porosity (void area $\%$ ) from top to bottom of sample AM2.5 (bottom) and AM3.5 (top).

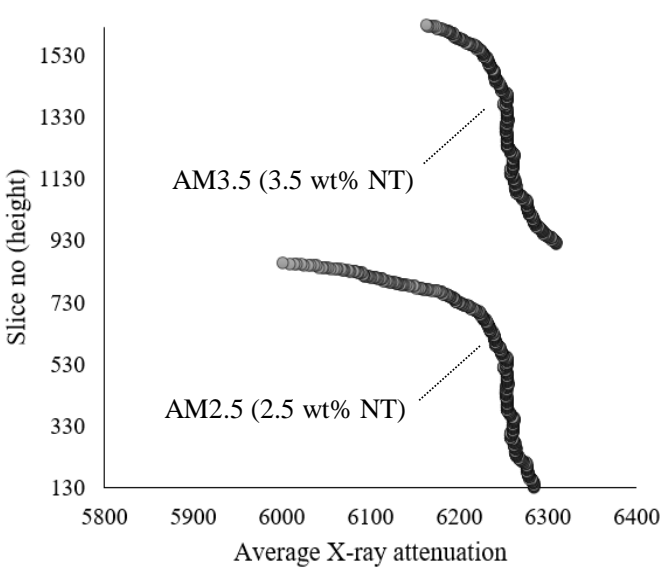

Figure 10: Average $\mathrm{x}$-ray attenuation of sample AM2.5 (bottom) and AM3.5 (top).

\subsection{Permeability}

The AM2.5 sample has presented the lowest permeability, i.e., $2.59 \times 10^{-16} \mathrm{~m}^{2}$ amongst all the NT mortar and pure mortar specimens. Comparing with the pure mortar sample, adding $2.5 \mathrm{wt} \% \mathrm{NT}$ can reduce the permeability by $32.1 \%$. This is a significant improvement in the durability of cement mortars. As the dosage of NT increases, the result shows a clear trend of increasing permeability of the NT cement mortar with NT content, up to $10 \mathrm{wt} \%$ (as illustrated in Figure 11).

We have also tested and benchmarked the permeability of the NT mortar samples against steel and sandstone which are known as two possible extremes of permeability for building materials. 
Steel should theoretically have a permeability of zero hence the obtained permeability of $2.82 \times$ $10^{-20} \mathrm{~m}^{2}$ arises from a combination of pressure/volume measurement error, leakage from connections, and bypass of fluid around the sample. This result therefore represents the lower bound of permeability that can be measured with the experimental setup. The sandstone has the highest permeability of $3.50 \times 10^{-15} \mathrm{~m}^{2}$.

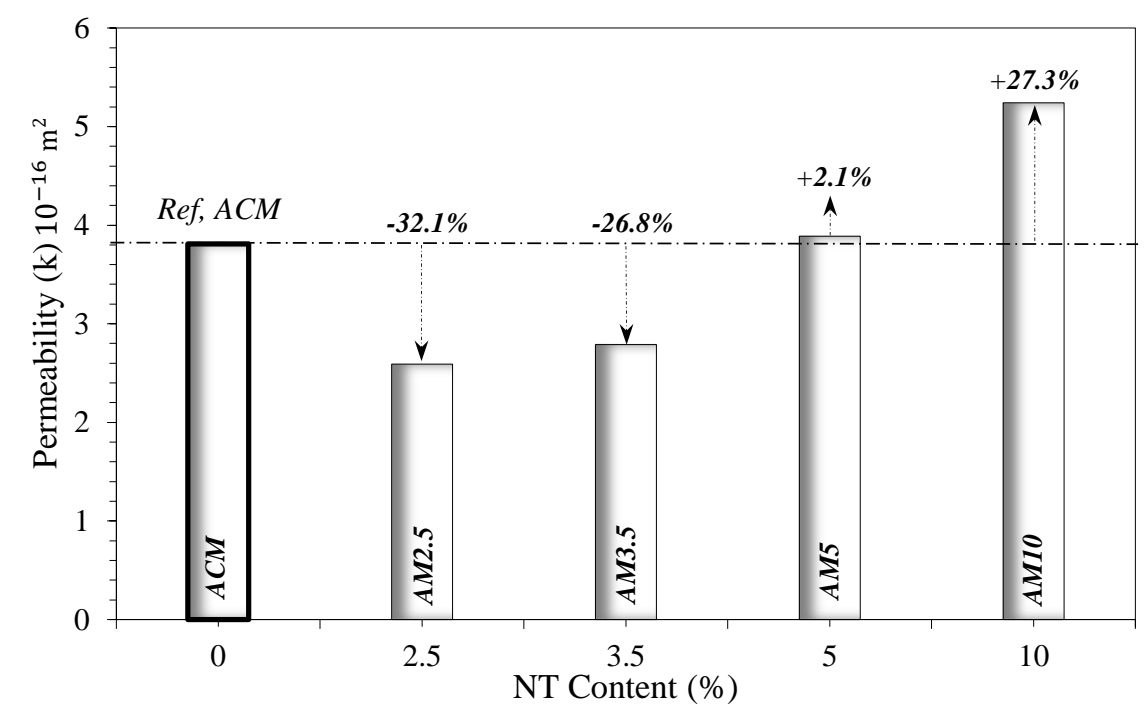

Figure 11: Relationships between permeability and NT content of mortars at 28 days.

It may also be noted that, adding NT up to about $5 \mathrm{wt} \%$ can reduce the permeability of mortars; the AM5 and ACM samples have very similar permeability values. Higher than $5 \mathrm{wt} \%$ dosage of NT will lead to higher permeability of mortars.

This could be caused by the fact that when the amount of NT exceeds the optimal value, (i.e., NT $>2.5 \mathrm{wt} \%$ ), the large specific surface area of the nanoparticles will absorb additional water and make the agglomeration phenomena easily reachable, leading to the formation of undisrupted pockets within the cement paste matrix and resulting in an increase in porosity of mortars. Such a process will certainly influence the permeability.

\subsection{Microstructural morphology}

Figures 12(a)-12(d) show SEM images of the microstructure of the cement mortars mixed with NT, i.e., (0 wt $\%, 2.5 \mathrm{wt} \%, 5 \mathrm{wt} \%$ and $10 \mathrm{wt} \%)$, at 28 days. Clearly different morphologies have been obtained amongst these samples. 
The reference sample ACM (Figure 12(a)) contains a moderate amount of small pores and medium size C-S-H structures. Fewer small needle-like and short columnar crystals are identified and possibly formed of ettringite or other AFt phases.

Increasing the NT content up to $2.5 \mathrm{wt} \%$ (AM2.5) leads to a more homogeneous microstructure compared to the reference mix (ACM). Also, C-S-H gel becomes larger in size which indicates a higher degree of hydration. Moreover, the microstructure of AM2.5 contains much smaller air-voids compared to sample ACM (Figure 12(b)). It can be seen from the SEM images, adding NT up to 2.5 wt\% resulted in an absence of needle shape structures and produced a homogeneous structure of CS-H compounds. By comparing with the SEM images of the reference sample in Figure 12(a), it is found that some conglobate materials appear in NT mortar samples. It can be speculated that these materials are the agglomerated nano titanium particles.

On increasing the NT to $5 \mathrm{wt} \%$, the C-S-H gel remained homogeneous and comparable to the 2.5 wt $\%$ NT sample. However, the 5 wt $\%$ NT sample now contained larger air-voids compared to the sample AM2.5 (Figure 12(c)). Moreover, more agglomerated NT particles were observed. When the added amount of NT reached $10 \mathrm{wt} \%$ (AM10), it was still possible to observe some needle-shaped AFt phases in the matrix.

However, small size C-S-H gels were formed with larger and more voids produced (Figure12(d)). The microstructure became isolated and defective. Figure 13 shows the SEM image and EDS analysis of the cement mortar modified by $2.5 \mathrm{wt} \% \mathrm{NT}$.

It can be seen from Figure 13(a) that the composition of sample AM2.5 mainly consisted of carbon (C), oxygen $(\mathrm{O})$, silicon $(\mathrm{Si})$, calcium $(\mathrm{Ca})$, and Ti. Additionally, with the help of EDS analysis (Figure 13(a, b)), a fact that C-S-H was grown on the surface of NT was verified, which shows that NT played a nucleation role in the cement hydration process. 


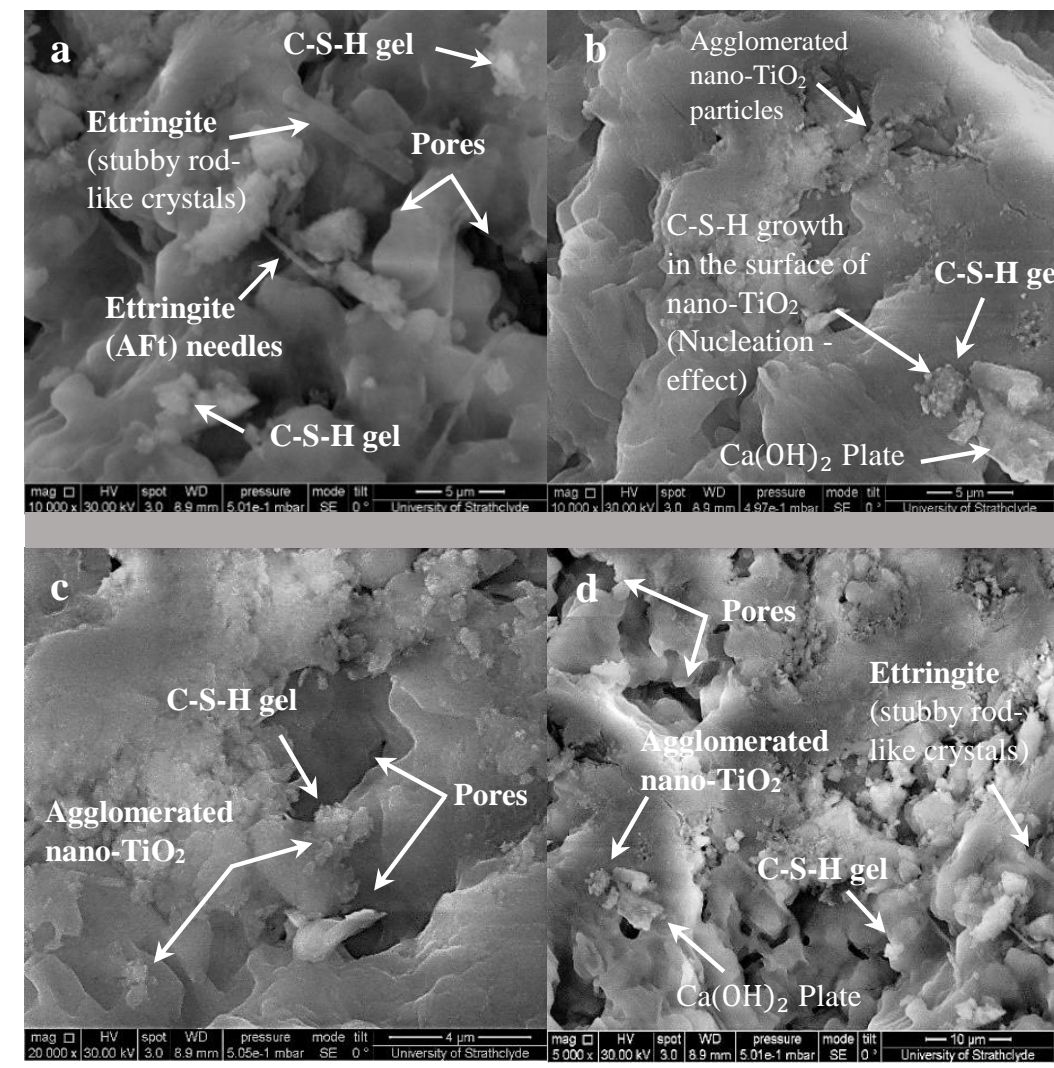

Figure 12: Typical SEM image of specimens with different additions of NT (a) $0 \%$; (b) $2.5 \%$; (c) $5 \%$; (d) $10 \%$ at 28 days curing.

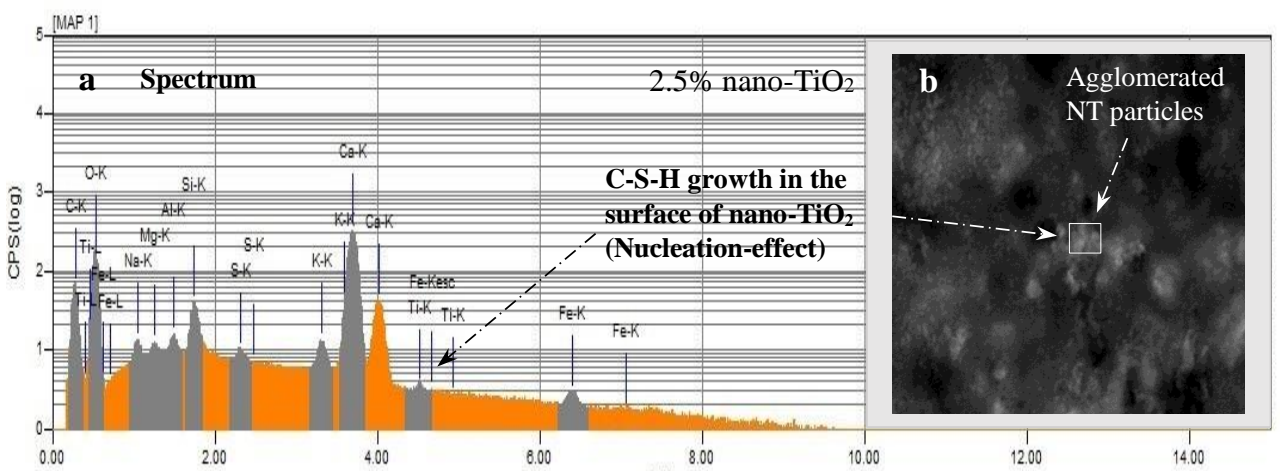

Figure 13: Typical EDS analysis (a) and SEEM image (b) of specimen and with $2.5 \%$ NT (AM3.5) at curing time 28 days.

\subsection{Nanoscale pore system by BET and BJH analysis}

The BET data carried out on the powdered samples indicates that the isotherm measured was of Type

IV, signifying monolayer-multilayer adsorption in the early part of the curve with a type $\mathrm{H} 3$ hysteresis loop between adsorption and desorption and capillary condensation in mesopores $(2 \mathrm{~nm}<\phi<50 \mathrm{~nm})$ and macropores $(\phi>50 \mathrm{~nm})$. The lack of any limiting adsorption at high $p / p^{0}$ suggests that the sample consists of plate-like particles giving rise to slit-like pores [23]. There is a clear trend of increasing surface area and pore volume of the NT cement mortars with NT content, over the range of $0 \mathrm{wt} \%$ to 
$10 \mathrm{wt} \%$ of the nanoparticles (Figure 14). This could stem from the formation of nanosized needleshaped products in the presence of the nanoparticles. The surface areas and the average pore diameter were calculated by the BET and BJH method, respectively and are presented in Table 5. The adsorption and desorption isotherms (BET) obtained on NT cement mortars, representing sample ACM (containing $0 \mathrm{wt} \% \mathrm{NT}$ ) which has the lowest pore volume and surface area, and sample AM10 (containing $10 \mathrm{wt} \% \mathrm{NT}$ ) which has the highest pore volume and surface area among the specimens are presented in Figure 15 and 16.

Table 5: Parameters of pore diameter, pore volume and surface area of cement mortars by BET and BJH method.

\begin{tabular}{ccccc}
\hline $\begin{array}{c}\text { Code number of } \\
\text { Cement Mortars }\end{array}$ & $\begin{array}{c}\text { Cement replacement } \\
(\mathrm{wt} \%) \text { Nano }-\mathrm{TiO}_{2}\end{array}$ & $\begin{array}{c}\text { Pore Diameter } \\
/ \mathrm{nm}\end{array}$ & $\begin{array}{c}\text { Pore Volume } \\
/ \mathrm{cm}^{3} \mathrm{~g}^{-1}\end{array}$ & $\begin{array}{c}\text { Surface Area } \\
/ \mathrm{m}^{2} \mathrm{~g}^{-1}\end{array}$ \\
\hline ACM & 0 & 19 & 0.015 & 3.58 \\
AM2.5 & 2.5 & 22.5 & 0.022 & 4.72 \\
AM3.5 & 3.5 & 25.2 & 0.028 & 5.53 \\
AM5 & 5 & 22.2 & 0.028 & 5.33 \\
AM10 & 10 & 20.5 & 0.043 & 9.98 \\
\hline
\end{tabular}

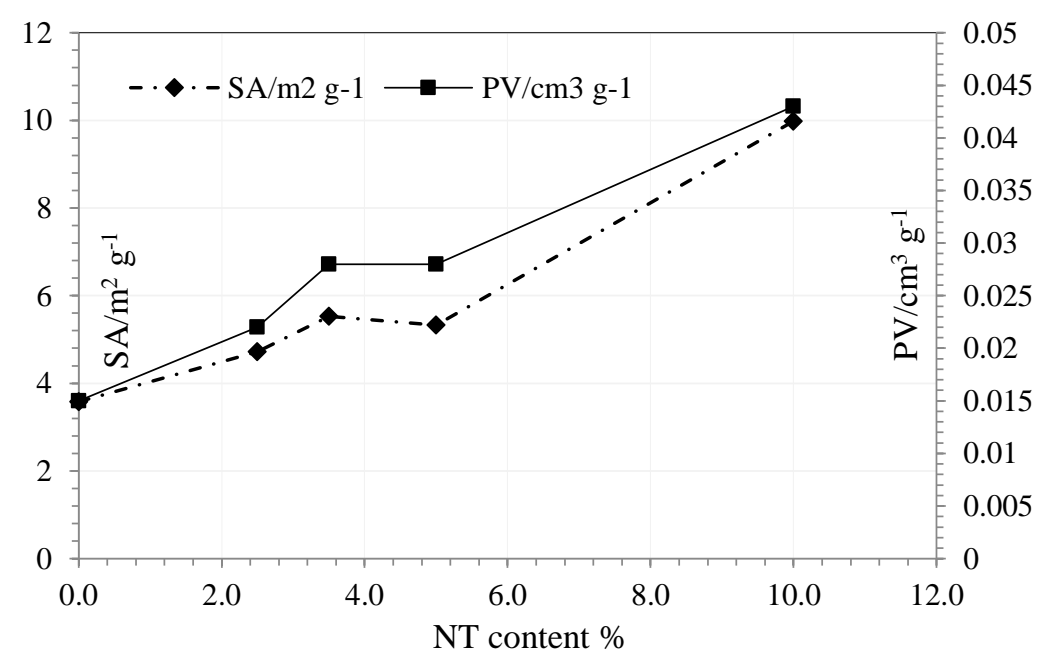

Figure 14: Relationships between surface area and pore volume with different dosages of NT at 28 days.

The inert $\mathrm{TiO}_{2}$ nanoparticles, through the increased surface area and provision of heterogeneous nucleation sites, accelerate the hydration reaction and increases the formation of the C-S-H gel [8]. It has been mentioned in the literature that beyond $5 \mathrm{wt} \%$, there could be an agglomeration of the nanoparticles and so, its impact on the properties of the composite would lessen. This is not revealed from the BET measurements which examines the nature of this interaction at the nanoscale level. 


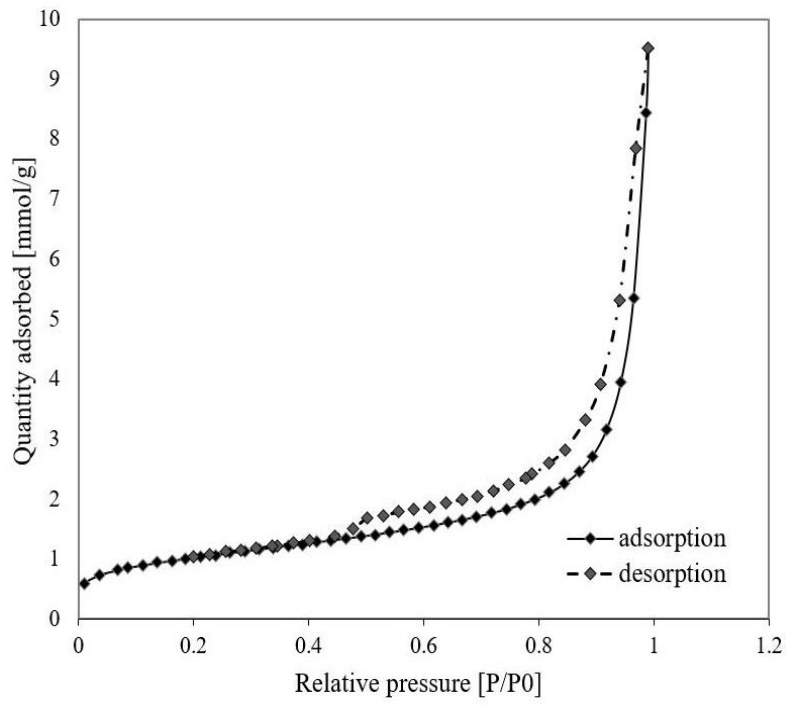

Figure 15: N2 Adsorption and Desorption isotherms of sample with $0 \%$ NT (ACM).

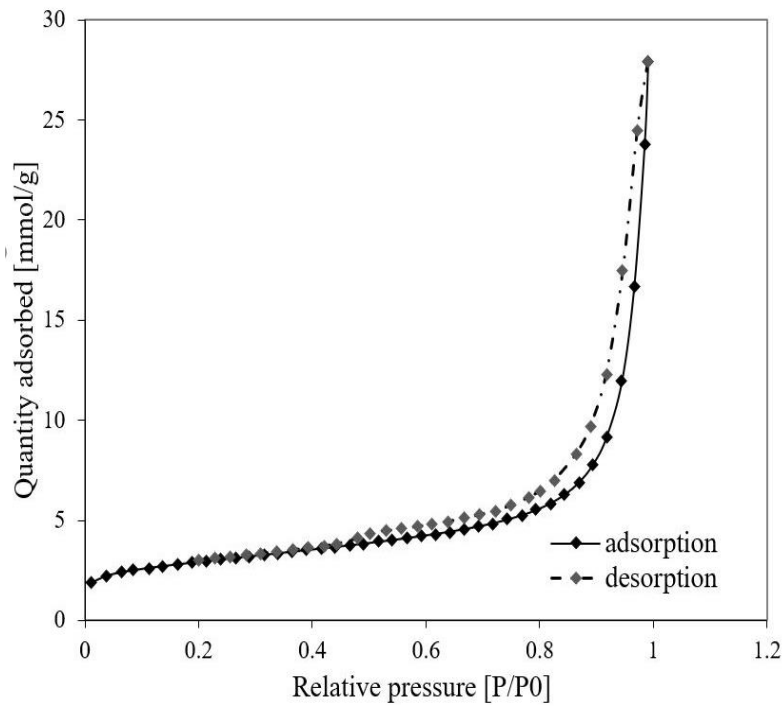

Figure 16: N2 Adsorption and Desorption isotherms of sample with $10 \%$ NT (AM10).

The pore volumes are evaluated using the $\mathrm{BJH}$ method from both nitrogen adsorption and desorption data and the results are presented in Figure 17 and 18 for the cement mortars with the highest pore volume (AM10) and the lowest pore volume (ACM). It can be clearly seen that the AM10 sample has considerably greater number of pores below $10 \mathrm{~nm}$ size than the ACM sample, i.e., pore volume is $0.005 / \mathrm{cm}^{3} \mathrm{~g}^{-1}$ compared to $0.002 / \mathrm{cm}^{3} \mathrm{~g}^{-1}$. For pores between $10 \mathrm{~nm}$ and $100 \mathrm{~nm}$ in size, the increase of pore volume is even higher when adding $10 \mathrm{wt} \%$ NT. This phenomenon shows that by adding NT in cement mortar, the nano pores (i.e., mainly in the size of $1 \mathrm{~nm}$ to100 $\mathrm{nm}$ ) are significantly increased.

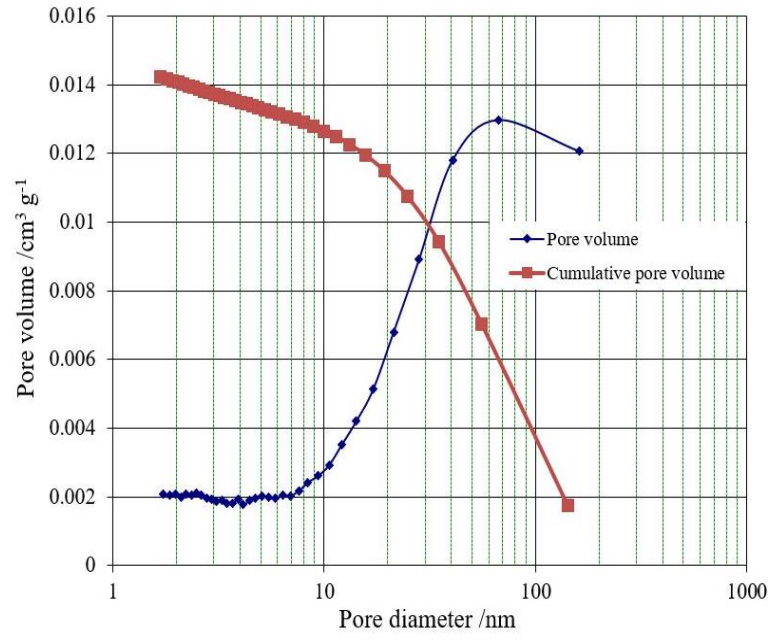

Figure 17: BJH adsorption of sample with $0 \%$ NT (ACM).

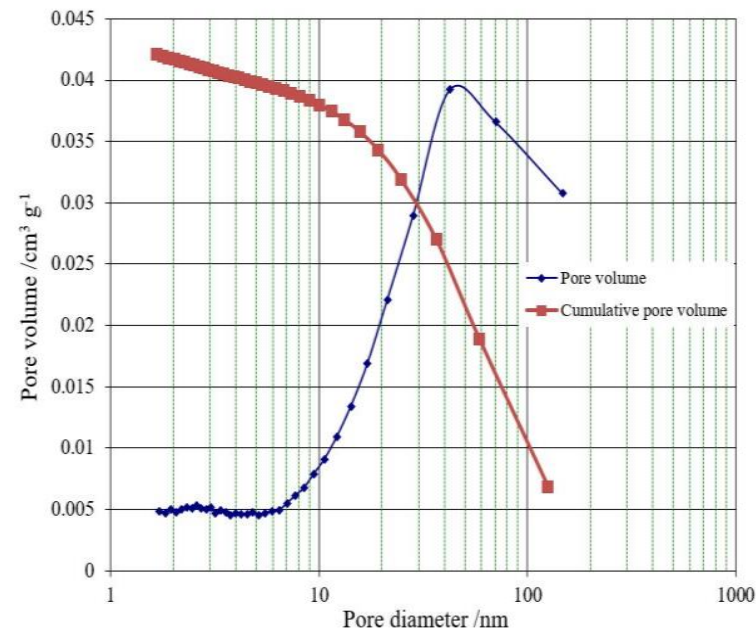

Figure 18: BJH adsorption of sample with $10 \%$ NT (AM10). 


\section{CONCLUSIONS}

In this paper, multiscale pore structure analysis of cement mortars incorporated with different percentages of NT has been investigated. Novel X-CT tests have been conducted to quantify and characterise the pore system for the NT mortar composite. SEM-EDS has been used to evaluate the phases of the microstructures of the composite. In addition, the durability of NT cement mortars was assessed by testing the water permeability using a high-pressure core holder with a sensitive and automated measurement capability. Further, BET analysis was carried out to examine the nanoscale pore system of the NT mortars, including the pore volume, pore shape and surface area. Specifically, the main conclusions can be drawn as follows:

(1) The pores of cement mortars mixed with $2.5 \mathrm{wt} \%$ to $3.5 \mathrm{wt} \%$ of NT are significantly refined and shift to nanosized pores (total average porosity reduced by $60.1 \%$ and $54.2 \%$ respectively).

(2) When the dosage of NT is more than $3.5 \mathrm{wt} \%$, the total pore volume and the number of pores begin to increase. However, when the amount of NT exceeds the optimal value, NT (>2.5 wt $\%)$, the recorded 3D volumetric void fractions and 2D area void fractions observed for AM5 (5.87, 5.95\%) are still lower than for the reference sample $\operatorname{ACM}(6.67 \%, 7.81 \%)$.

(3) The permeability of cement mortars with $2.5 \mathrm{wt} \%$ to $3.5 \mathrm{wt} \%$ NT inclusions are significantly decreased (permeability reduced by $32.1 \%$ and $26.8 \%$ respectively).

(4) SEM and EDS results indicate, when NT dosage is in the region of $2.5 \mathrm{wt} \%$, the surface morphology of the cement matrix becomes denser. This is owing to the fact that NT promotes the early hydration and acts as an external nucleation to promote the generation of C-S-H gel, ultimately improving the strength. Simultaneously, the pores of cement mortars are better-filled.

(5) There is a clear trend of increasing surface area and pore volume of the cement mortars with NT content, over the range $0 \mathrm{wt} \%$ to $10 \mathrm{wt} \%$ of the nanoparticles. This could stem from the formation of nanosized needle-shaped products in the presence of the NT particles. 


\section{Conflict of Interests}

The authors declare that there is no conflict of interests regarding the publication of this paper.

\section{Acknowledgements}

EPSRC Studentship awarded from the University of Strathclyde, UK, for DS is thankfully acknowledged.

\section{References}

[1]. Poon. C. S. Photocatalytic cementitious materials: influence of the microstructure of cement paste on photocatalytic pollution, Environ. Sci. Technol, vol. 43, no.10, pp. 8948-8951, 2009.

[2]. Strini. A, Schiavi. L, and Cassese. S. Measurement of benzene, toluene, ethylbenzene, and o-xylene gas phase photo degradation by titanium dioxide dispersed in concrete using a mixed flow reactor, Appl. Catal. B, vol. 61(1), pp. 90-97, 2005.

[3]. Zhou. P, and Jaroniec. M. "Enhanced photocatalytic $\mathrm{CO}_{2}$-reduction activity of anatase $\mathrm{TiO}_{2}$ by Coexposed $\{001\}$ and $\{101\}$ facets," Journal of the American Chemical Society, vol. 136, no. 25, pp. 8839-8842, 2014

[4]. Chen. J, and Poon. C. S. Photocatalytic activity of titanium dioxide modified concrete materials influence of utilizing recycled glass cullets as aggregates, J. Environ. Manage. vol 90, pp. 3435-3442, 2009.

[5]. Demeestere K, Dewulf J, Witte B. D, Beeldens A, and Langenhove. H. V. "Heterogeneous photocatalytic removal of toluene from air on building materials enriched with $\mathrm{TiO}_{2}$," Building and Environment, vol. 43, no. 4, pp. 405-414, 2008.

[6]. Zhang, Mao-hua, and Hui Li. "Pore structure and chloride permeability of concrete containing nanoparticles for pavement". Construction and Building Materials, vol 25(2), pp. 608-616, 2011.

[7]. Lackhoff. M, Prieto. X, Nestle. N, Dehn. F, and Niessner. R. Photocatalytic activity of semiconductormodified cement-Influence of semiconductor type and cement ageing. Appl. Catal. B Environ, vol 43, pp. 205-206, 2003.

[8] Jayapalan. A. R, Lee. B. Y, Fredrich. S. M, and Kurtis K. E. Influence of Additions of Anatase $\mathrm{TiO}_{2}$ Nanoparticles on Early-Age Properties of Cement-Based Materials. Transp. Res. Rec. J. Transp. Res. Board. 2141, pp. 41-46, 2010.

[9]. Lee. B. Y, and Kurtis K. E. Influence of $\mathrm{TiO}_{2}$ nanoparticles on early $\mathrm{C}_{3} \mathrm{~S}$ hydration. J. Am. Ceram. Soc, vol 93, pp. 3399-3405, 2010.

[10]. Chen. J, Kou. S. C, and Poon C. S. Hydration and properties of nano-TiO ${ }_{2}$ blended cement composites. Cement Concrete. Composite, vol 34, pp. 642-649, 2012.

[11]. Nazari, A. The effects of curing medium on flexural strength and water permeability of concrete incorporating TiO2 nanoparticles. Mater. Struct, vol 44, pp. 773-786, 2011.

[12]. Feng. D, Xie. N, Gong. C, Leng. Z, Xiao. H, and Li. H. Portland cement paste modified by $\mathrm{TiO}_{2}$ nanoparticles: A microstructure perspective. Ind. Eng. Chem. Res, vol 52, pp. 11575-11582, 2013.

[13]. BS-EN197. Cement-part 1. Composition, specifications and conformity criteria for common cements. London: BSI publications, 2000. 
[14]. Lucas. S, Ferreira. V, Aguiar. De, and J.B. Incorporation of titanium dioxide nanoparticles in mortarsInfluence of microstructure in the hardened state properties and photocatalytic activity. Cement and Concrete. Res, vol 43, pp. 112-120, 2013.

[15]. Meng. T, Yu. Y, Qian. X, Zhan. S, and Qian. K. Effect of nano-TiO ${ }_{2}$ on the mechanical properties of cement mortar. Construction and Building Materials, vol 29, pp. 240-245, 2012.

[16]. BS-EN12350-2. Testing fresh concrete part 2: Slump-test. London: BSI publication, 2009.

[17]. ASTM C511. Standard Specification for Mixing Rooms, Moist Cabinets, Moist Rooms, and Water Storage Tanks Used in the Testing of Hydraulic Cements and Concretes, USA, 2019.

[18]. Rattanasak. U, and Kendall. K. Pore Structure of Cement / Pozzolan Composites by X-Ray Microtomography. Cement and Concrete Research, vol 35(4), pp. 637-640, 2005.

[19]. Gallucci. E. Scrivener. K, and Groso. A. 3D Experimental Investigation of the Microstructure of Cement Pastes Using Synchrotron X-Ray Microtomography. Cement and Concrete Research, vol 37(3) pp. 360-368, 2007.

[20]. Diamond. S. Mercury porosimetry: an inappropriate method for the measurement of pore size distributions in cement-based materials. Cem Concr Res, vol 30(10), pp. 1518-1525, 2000.

[21]. Bentz. D.P, Halleck P. M, Grader. A. S, and Roberts J. W. Four-dimensional X-ray microtomography study of water movement during internal curing. In: Proceedings of the international RILEM conferencevolume changes of hardening concrete: testing and mitigation, pp 11-20, 2006.

[22]. Lu. S, Landis. E, and Keane. D. X-ray microtomographic studies of pore structure and permeability in Portland cement concrete. Mater Struct, vol 39(6), pp. 611-620, 2006.

[23]. Everett. D.H, Sing. K. S. W, Haul. R. A. W, Moscou. L, Pierotti. R. A, Rouquerol. J, and Siemieniewska. T. "Reporting physisorption data for gas/solid systems with Special Reference in the Determination of Surface Area and Porosity", Pure \& Appl. Chem, vol 57 (4), pp. 602-618, 1985. 